\title{
Influence of Heat Treatments on Microstructure and Mechanical Properties of Ti-26Nb Alloy Elaborated In Situ by Laser Additive Manufacturing with Ti and $\mathrm{Nb}$ Mixed Powder
}

\author{
Jing Wei ${ }^{1}$, Hongji Sun ${ }^{1}$, Dechuang Zhang ${ }^{2, *}$, Lunjun Gong ${ }^{2}$, Jianguo Lin ${ }^{1, *}$ and Cuie Wen ${ }^{3}$ \\ 1 School of Materials Science and Engineering, Xiangtan University, Xiangtan 411105, China; \\ weijing19930624@163.com (J.W.); sun_hong_ji@163.com (H.S.) \\ 2 Key Laboratory of Materials Design and Preparation Technology of Hunan Province, Xiangtan University, \\ Xiangtan 411105, China; ljgong@xtu.edu.cn \\ 3 School of Aerospace, Mechanical and Manufacturing Engineering, RMIT University, Melbourne 3083, \\ Australia; cuie.wen@rmit.edu.au \\ * $\quad$ Correspondence: dczhang@xtu.edu.cn (D.Z.); lin_j_g@xtu.edu.cn (J.L.); Tel.: +86-731-5829-8119 (D.Z. \& J.L.)
}

Received: 25 November 2018; Accepted: 18 December 2018; Published: 25 December 2018

\begin{abstract}
In the present work, a Ti-26Nb alloy was elaborated in situ by laser additive manufacturing (LAM) with $\mathrm{Ti}$ and $\mathrm{Nb}$ mixed powders. The alloys were annealed at temperatures ranging from $650{ }^{\circ} \mathrm{C}$ to $925^{\circ} \mathrm{C}$, and the effects of the annealing temperature on the microstructure and mechanical properties were investigated. It has been found that the microstructure of the as-deposited alloy obtained in the present conditions is characterized by columnar prior $\beta$ grains with a relatively strong $<001>$ fiber texture in the build direction. The as-deposited alloy exhibits extremely high strength, and its ultimate tensile strength and yield strength are about $799 \mathrm{MPa}$ and $768 \mathrm{MPa}$, respectively. The annealing temperature has significant effects on the microstructure and mechanical properties of the alloys. Annealing treatment can promote the dissolution of unmelted $\mathrm{Nb}$ particles and eliminate the micro-segregation of $\mathrm{Nb}$ at the elliptical-shaped grain boundaries, while increasing the grain size of the alloy. With an increase in annealing temperature, the strength of the alloy decreases but the ductility increases. The alloy annealed at $850{ }^{\circ} \mathrm{C}$ exhibits a balance of strength and ductility.
\end{abstract}

Keywords: heat treatment; in situ alloying; laser additive manufacturing; mechanical properties; microstructure; $\mathrm{Ti}-\mathrm{Nb}$ alloy

\section{Introduction}

Beta $(\beta)$ titanium (Ti) alloys containing non-cytotoxic elements such as niobium $(\mathrm{Nb})$, zirconium $(\mathrm{Zr})$, tantalum $(\mathrm{Ta})$, tin $(\mathrm{Sn})$, and molybdenum $(\mathrm{Mo})$ have been intensively studied for applications in biomedical domains [1-5]. Among these, Ti-Nb alloys have attracted particular attention due to their high strength (600 MPa) and their very low elastic modulus (50 GPa), close to that of cortical bone (30 GPa), which was observed to reduce the stress-shielding phenomenon [6]. These alloys are considered to be potential substitute materials for conventional materials such as $\mathrm{Ti}-\mathrm{Ni}$ or $\mathrm{Ti}-6 \mathrm{Al}-4 \mathrm{~V}$ in order to prevent the release of toxic nickel $(\mathrm{Ni})$, aluminium (Al), or vanadium (V) ions into the human body [7-11].

Recently, laser additive manufacturing (LAM), based on coaxed powder melting and rapid solidification through layer-upon-layer deposition, has attracted a great deal of attention in the fabrication of fully dense near net-shaped metallic components [12-15]. It has several significant advantages over traditional manufacturing methods, such as a wide range of material forms, 
a simple manufacturing process for complex parts, short production cycle, raw material saving, excellent performance, etc. So it is an effective method for the personal customization of biological implants.

Generally, the powders for LAM are obtained from a prealloyed material that is converted into powder by plasma arc or gas atomization to achieve spherical particles with a particle size between 10 and $110 \mu \mathrm{m}$. In the case of Ti-Nb alloys, their high melting temperatures make it very complicated to produce powders in this way. So the $\mathrm{Ti}-\mathrm{Nb}$ alloy powders that can be applied to direct laser metal-forming are still rare or even commercially unavailable. Recently, some researchers attempted to fabricate $\mathrm{Ti}-\mathrm{Nb}$ alloys using selective laser melting (SLM) with mixtures of elemental powders of pure $\mathrm{Ti}$ and $\mathrm{Nb}$. For example, Fischer et al. [16] fabricated Ti-26Nb (at.\%) using SLM with elemental Ti and $\mathrm{Nb}$ mixed powders with high energy levels, and the alloy exhibited a homogeneous and dense microstructure with a $\beta$ structure. Wang et al. [17] also fabricated Ti-Nb alloys with different $\mathrm{Nb}$ content using the same method and investigated the effects of $\mathrm{Nb}$ content on the microstructure and mechanical properties; they found that SLM could be used for in situ fabrication of $\mathrm{Ti}-\mathrm{Nb}$ bone implants with tailored mechanical and biomedical properties by adjusting the level of $\mathrm{Nb}$.

It has been reported that, compared to the microstructure achieved with conventional casting and forging, Ti alloys prepared using LAM usually exhibit a quite different microstructure due to repeated rapid solidification and rapid annealing during laser forming. Moreover, defects can be found in the as-deposited part, such as inconsistency in the structure and stability of mechanical properties, residual stress, and pores, which can weaken the mechanical properties of the alloys. Post-heat treatment can have an important influence on the microstructure and properties of the alloys [18-20]. However, microstructure transformation after heat treatment of as-deposited $\mathrm{Ti}-\mathrm{Nb}$ alloys has rarely been investigated. Therefore, a deeper understanding of the microstructural evolution of $\mathrm{Ti}-\mathrm{Nb}$ formed by LAM during heat treatment would allow improvement of the mechanical mechanical of these alloys. In the present work, a Ti-26at.\% $\mathrm{Nb}$ alloy was prepared by directly melting a mixture of elemental $\mathrm{Ti}$ and $\mathrm{Nb}$ powders under a laser beam. The alloy was annealed at temperatures ranging from $650{ }^{\circ} \mathrm{C}$ to $925^{\circ} \mathrm{C}$ and the influence of the annealing temperature on the microstructure evolution and mechanical properties of the alloy was investigated.

\section{Experimental Methods}

\subsection{Material Manufacturing}

Commercial gas-atomized pure Ti powder (purity 99.99\%, Changsha Tianjiu Metal Materials Co. Ltd., Changsha, China) with a particle size of $45-105 \mu \mathrm{m}$ and pure $\mathrm{Nb}$ powder (purity $99.99 \%$, Changsha Tianjiu Metal Materials Co. Ltd., Changsha, China) with a particle size of 48-75 $\mu \mathrm{m}$ were used as the raw materials. The two powders were mixed in the weight ratio $\mathrm{Ti}: \mathrm{Nb}=59.5: 40.5$ (namely 74:26 in atomic ratio) by ball milling for $1 \mathrm{~h}$. Figure 1 shows the morphologies of the Ti and $\mathrm{Nb}$ powders and the mixtures. It is clear that the Ti powder has regular spheres with the presence of satellites (Figure 1a), whereas the $\mathrm{Nb}$ has irregular shapes (Figure 1b). After mixing, the $\mathrm{Nb}$ particles were uniformly distributed around the Ti particles (see Figure 1c). The melting point of $\mathrm{Nb}\left(2477^{\circ} \mathrm{C}\right)$ is much higher than that of $\operatorname{Ti}\left(1668^{\circ} \mathrm{C}\right)$. To facilitate better melting of the $\mathrm{Nb}$ and its faster diffusion in $\mathrm{Ti}, \mathrm{Nb}$ powder with a smaller particle size than the Ti powder was used in the present work. 

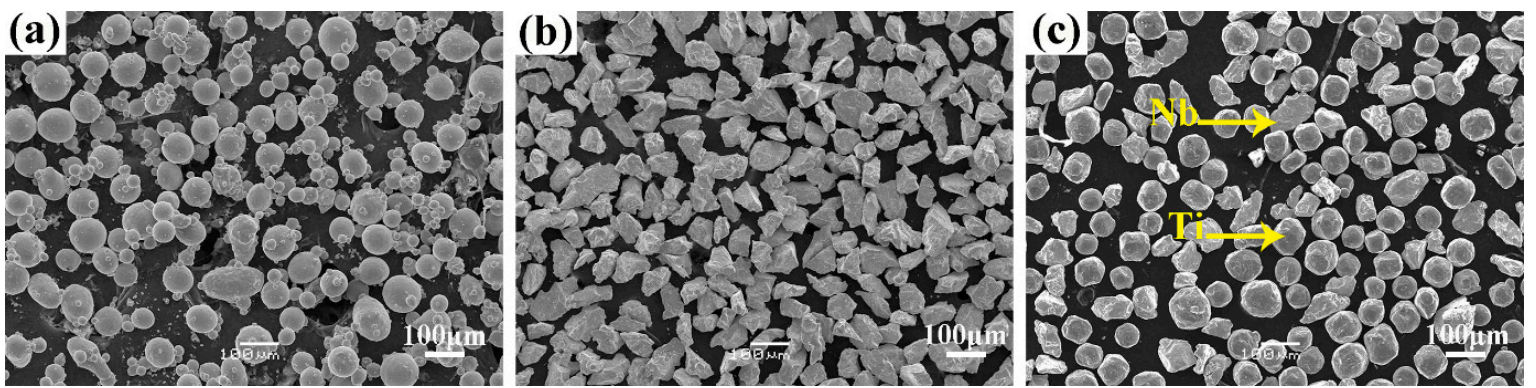

Figure 1. Scanning electron microscope (SEM) images of feedstock powders: (a) pure Ti; (b) pure $\mathrm{Nb}$; and (c) $\mathrm{Ti}-26 \mathrm{Nb}$ powder mixture.

A square block sample of the obtained Ti-26Nb alloy with dimensions of $400 \mathrm{~mm} \times 350 \mathrm{~mm} \times$ $230 \mathrm{~mm}$ (see Figure 2) was fabricated by a LAM process on a YLS-4000-CL machine (IPG photonics corporation, Oxford, MA, USA), in which a fiber laser was produced by the IPG photonics corporation and the powder was fed in coaxial feeding mode with argon as the carrier gas. SD, LD, and BD represent the scanning direction, lateral direction, and build direction, respectively. The laser-deposition processing parameters were: laser nominal output power $750 \mathrm{~W}$; laser beam diameter $2.5 \mathrm{~mm}$; scanning speed $480 \mathrm{~mm} / \mathrm{min}$; and powder feed rate $2.2 \mathrm{~g} / \mathrm{min}$.

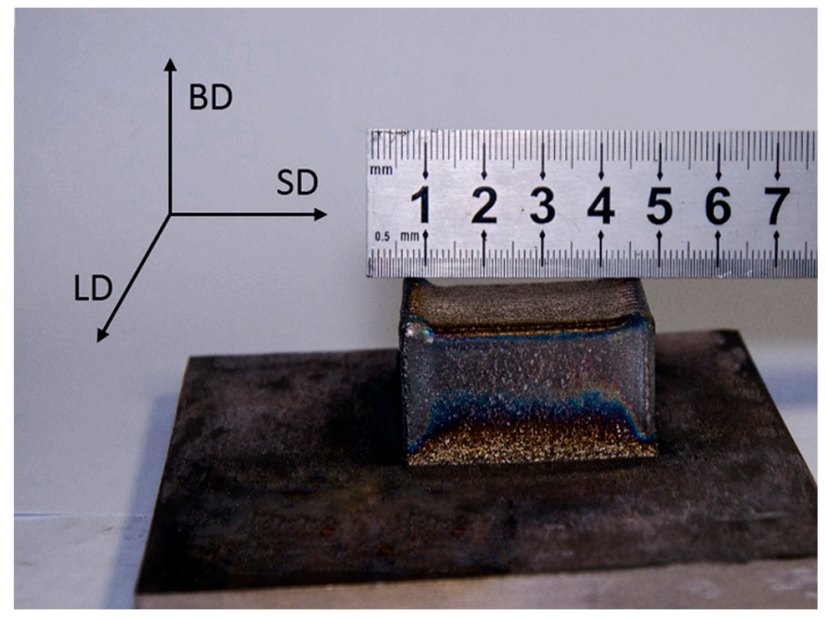

Figure 2. Bulk Ti-26Nb sample fabricated by laser additive manufacturing (LAM).

\subsection{Heat Treatment}

The samples for heat treatment were sectioned along the BD with dimensions of $25 \mathrm{~mm}$ in length (BD), $10 \mathrm{~mm}$ in width (SD), and $1.2 \mathrm{~mm}$ in thickness (LD). The samples were vacuum encapsulated in quartz tubes and annealed at temperatures ranging from $650{ }^{\circ} \mathrm{C}$ to $925^{\circ} \mathrm{C}$ for a duration of $0.5 \mathrm{~h}$ followed by water quenching, as listed in Table 1.

Table 1. Details of heat treatment for LAM Ti-26Nb alloys.

\begin{tabular}{cc}
\hline Sample No. & Heat Treatment \\
\hline 1 & $650^{\circ} \mathrm{C} / 0.5 \mathrm{~h}+\mathrm{WQ}$ \\
2 & $750^{\circ} \mathrm{C} / 0.5 \mathrm{~h}+\mathrm{WQ}$ \\
3 & $850^{\circ} \mathrm{C} / 0.5 \mathrm{~h}+\mathrm{WQ}$ \\
4 & $925^{\circ} \mathrm{C} / 0.5 \mathrm{~h}+\mathrm{WQ}$ \\
\hline
\end{tabular}

Note: WQ is water quenching. 


\subsection{Microstructure Characterization}

The microstructures of the alloy samples before and after heat treatment were characterized by optical microscopy (OM; BX51M, Olympus, Tokyo, Japan), scanning electron microscopy (SEM; MIRA3 LMU, Tescan, Brno, Czech), and X-ray diffraction (XRD; D/max 2500, Rigaku, Tokyo, Japan). Grain size and grain orientation were determined by electron backscatter diffraction (EBSD; HKL, Oxford, UK). Several regions in the samples were chosen for the EBSD analysis, and average grain size and grain orientations were determined by statistical analysis.

\subsection{Mechanical Property Testing}

Tensile tests of the Ti-26Nb alloy were carried out on an Instron 5569 universal testing machine (Instron, Boston, MA, USA). The samples for the tests were cut from the middle section of the block prepared by LAM with a gauge section of $1 \mathrm{~mm} \times 2.5 \mathrm{~mm} \times 8 \mathrm{~mm}$, the geometry of which is schematically shown in Figure 3. All specimens are shown along the BD. Three samples were measured for each condition in order to reduce measurement error.

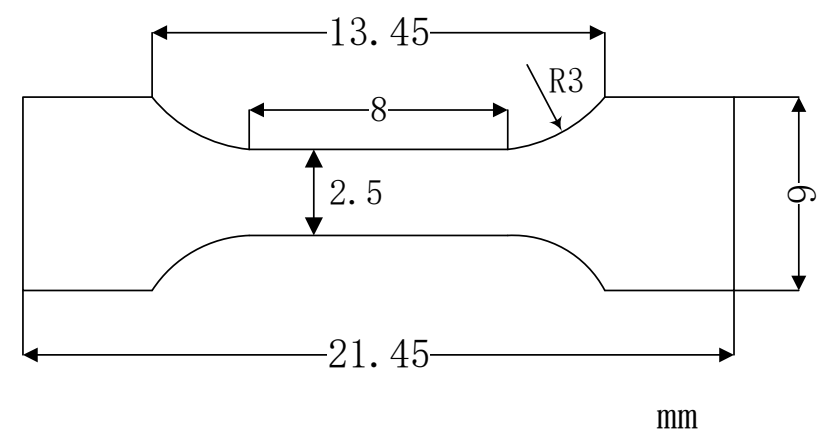

Figure 3. Schematic geometry of tensile specimen.

For comparison, another Ti-26Nb alloy was prepared using a conventional arc melting method with pure $\mathrm{Ti}$ and $\mathrm{Nb}$ as the raw materials. The ingot was hot-rolled by $90 \%$ in thickness, then tensile testing of the mechanical properties according to the above method was also carried out in the same conditions.

\section{Results and Discussion}

\subsection{Phase Composition}

Figure 4 shows the X-ray diffraction (XRD) patterns of the Ti-26Nb alloy fabricated by LAM and after annealing at different temperatures for $0.5 \mathrm{~h}$. It can be seen that the as-deposited alloy shows a single $\beta$ phase with a body-centered cubic (bcc) structure. After annealing at $650{ }^{\circ} \mathrm{C}$ for $0.5 \mathrm{~h}$, diffraction peaks from an $\alpha$ phase could be seen in the XRD pattern of the alloy, implying that an $\alpha$ phase precipitated in the alloy. As the annealing temperature increased to $925^{\circ} \mathrm{C}$, the peaks from the $\alpha$ phase completely disappeared. By careful comparison, it can be seen that the diffraction peaks of the $\beta$ phase on the XRD pattern of the alloy after annealing have slightly shifted to the left relative to the as-deposited sample (as shown in Figure 4). This implies that more $\mathrm{Nb}$ atoms have dissolved in the Ti lattice. This is because the radius of the solute atom $\mathrm{Nb}$ is slightly larger than that of the Ti atom, and thus a higher concentration of $\mathrm{Nb}$ leads to an increase in the lattice constant of the $\beta$ phase. 


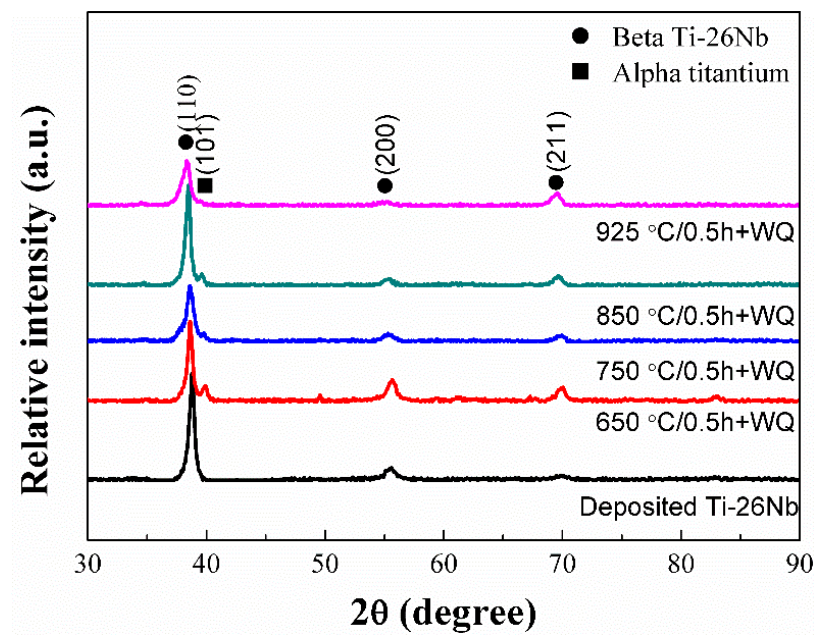

Figure 4. X-ray diffraction (XRD) patterns of LAM-processed Ti-26Nb alloys after annealing treatment at different temperatures.

\subsection{Microstructure}

Figure 5 illustrates the microstructure of the as-deposited Ti-26Nb alloy. It is clear that multilayer deposits with uniform thickness and regular distribution have been formed in the as-deposited Ti- $26 \mathrm{Nb}$ alloy. The prior $\beta$ phase with columnar grains oriented more or less in the $\mathrm{BD}$, which penetrate the multilayer cladding layer, can be observed (see Figure 5a). The special formation mechanism of columnar grains has been clearly explained in previous work [21]. Some unmelted $\mathrm{Nb}$ can be observed in the Ti- $\mathrm{Nb}$ alloy due to its relatively high melting temperature of $2477^{\circ} \mathrm{C}$, as shown in Figure $5 \mathrm{a}$. The results indicate that the applied energy density of the LAM process is sufficient to completely melt the Ti powder, but some of the larger $\mathrm{Nb}$ particles are only partially melted. Similar behavior was also found in a previous report [22]. Moreover, some pores can be seen on the surface of the sample, which may have been caused by ball formation and gas inclusion generated during the melting and remelting process [23].
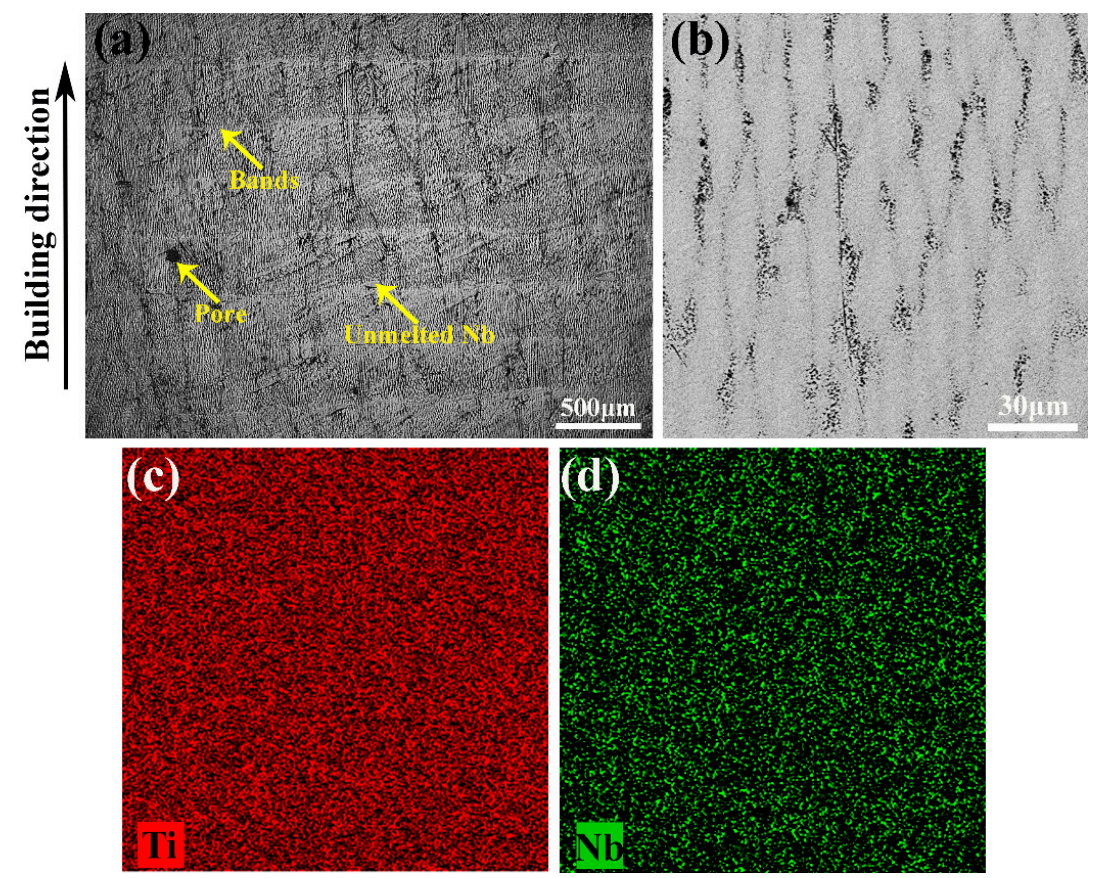

Figure 5. (a) and (b) Microstructures of as-deposited Ti-26Nb alloy; (c) and (d) elemental mapping images of as-deposited $\mathrm{Ti}-26 \mathrm{Nb}$ of $(\mathbf{b})$. 
A magnified image reveals that some ultra-fine elliptical-shaped grains (dendritic grains) with dimensions of $\sim 10 \mu \mathrm{m}$ in width and $\sim 80 \mu \mathrm{m}$ in length were formed in the representative regions (see Figure 5b). This may be attributed to the fact that the solidified layer acts as a substrate for the solidification of the melt, leading to the formation of elliptical-shaped grains perpendicular to the solidification front [24]. Moreover, the elliptical grains grew in a wavelike fashion and their boundaries are poor in $\mathrm{Nb}$, as seen in Figure $5 \mathrm{c}, \mathrm{d}$.

Figure 6 shows the distributions of $\mathrm{Ti}$ and $\mathrm{Nb}$ elements in the molten pool of $\mathrm{Ti}-26 \mathrm{Nb}$ alloy. It can be seen that the $\mathrm{Ti}$ and $\mathrm{Nb}$ content at the melt pool boundaries (MPBs) is identical to that inside of the molten pool, implying that the solidification of the molten pool is completed in a short time, which is very different from conventional casting. As a result, the $\mathrm{Nb}$ particles do not have enough time to sink to the bottom of the molten pool and thus remain.

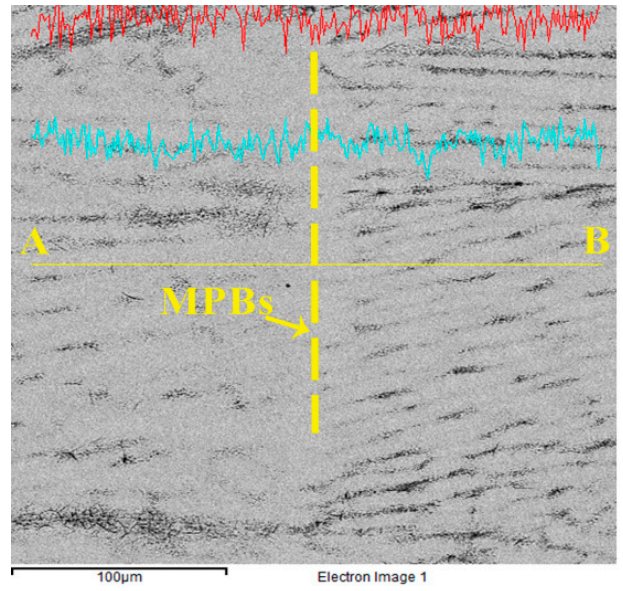

(a)

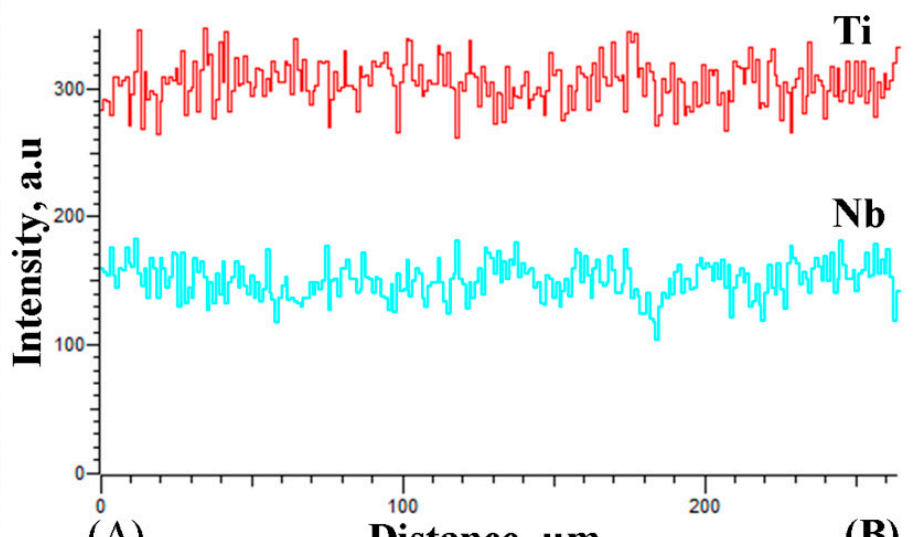

(b)

Figure 6. (a) Energy-dispersive $X$-ray spectroscopy (EDS) line scanning of melt pool in lateral plane of $\mathrm{Ti}-26 \mathrm{Nb}$ alloy (b) corresponding line scanning results of $\mathrm{Ti}$ and $\mathrm{Nb}$ elements.

To investigate the effects of the heat treatment on the microstructure of the alloy fabricated by LAM, the as-deposited alloy samples were annealed at temperatures ranging from $650{ }^{\circ} \mathrm{C}$ to $925^{\circ} \mathrm{C}$. Figure 7 illustrates the microstructures of the samples after annealing at the different temperatures.

For the sample annealed at $650{ }^{\circ} \mathrm{C}$ for $0.5 \mathrm{~h}$, elliptical grains began to grow and their size distribution became more uniform (as shown in Figure 7a) as compared to as-deposited sample. Close observation reveals that the some fine acicular secondary $\alpha_{\mathrm{S}}$ phases precipitated in the areas poor in $\mathrm{Nb}$ atoms in the alloys annealed at $650^{\circ} \mathrm{C}$ and $750{ }^{\circ} \mathrm{C}$, as shown in the inset of Figure $7 \mathrm{c}, \mathrm{d}$ ). As the annealed temperature increased to $850{ }^{\circ} \mathrm{C}$, the boundaries of the ellipses became unclear, implying the dissolution of the dendritic grains due to the diffusion of $\mathrm{Nb}$ atoms. Moreover, almost all the $\alpha_{S}$ phases disappeared in the alloys as the annealing temperature increased over $850{ }^{\circ} \mathrm{C}$, and the alloy that annealed at $925^{\circ} \mathrm{C}$ exhibited an even microstructure with all $\beta$ phases (see Figure 7e,f). This is consistented with the XRD analysis.

Figure 8 illustrates the $\mathrm{Nb}$ concentration in the elliptical-shaped grains and the grain boundaries as obtained by energy-dispersive X-ray spectroscopy (EDS) analysis. It can be seen that, for the as-deposited alloy, the $\mathrm{Nb}$ content at the grain boundaries area is much lower than in the elliptical grains. After annealing at $650{ }^{\circ} \mathrm{C}$, the $\mathrm{Nb}$ content at the grain boundaries increased to become close to that inside the grains, implying the diffusion of $\mathrm{Nb}$ from inside to the grain boundaries during the annealing treatment. As the annealing temperature further increased, the $\mathrm{Nb}$ content both inside and at the boundaries of the grains slightly increased, implying the dissolution of the unmelted $\mathrm{Nb}$ particles. 

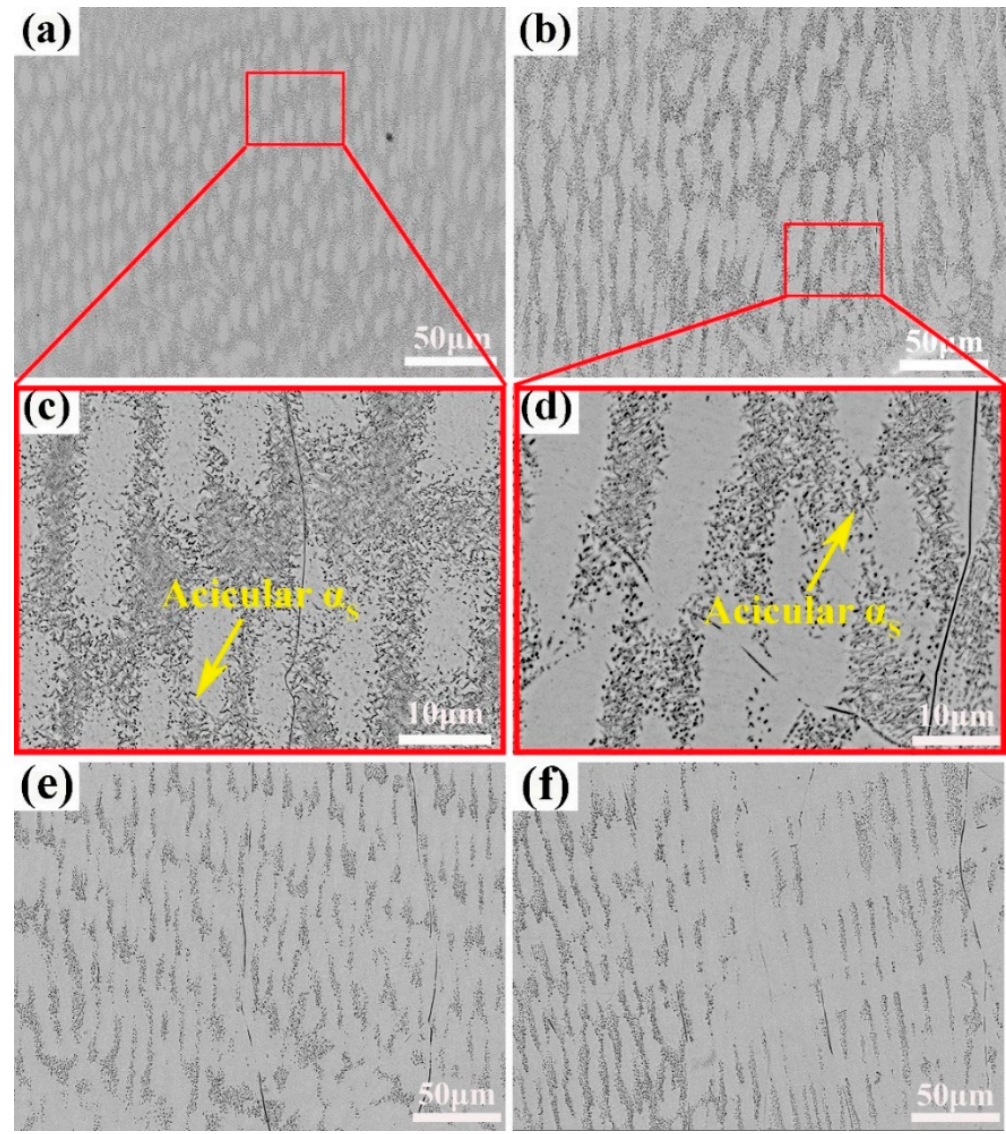

Figure 7. Microstructures of annealed samples at different temperatures for $0.5 \mathrm{~h}$ : (a) $650{ }^{\circ} \mathrm{C}$; (b) $750{ }^{\circ} \mathrm{C}$; (c) and (d) corresponding high-magnification morphologies of (a) and (b), respectively; (e) $850{ }^{\circ} \mathrm{C}$; (f) $925{ }^{\circ} \mathrm{C}$.

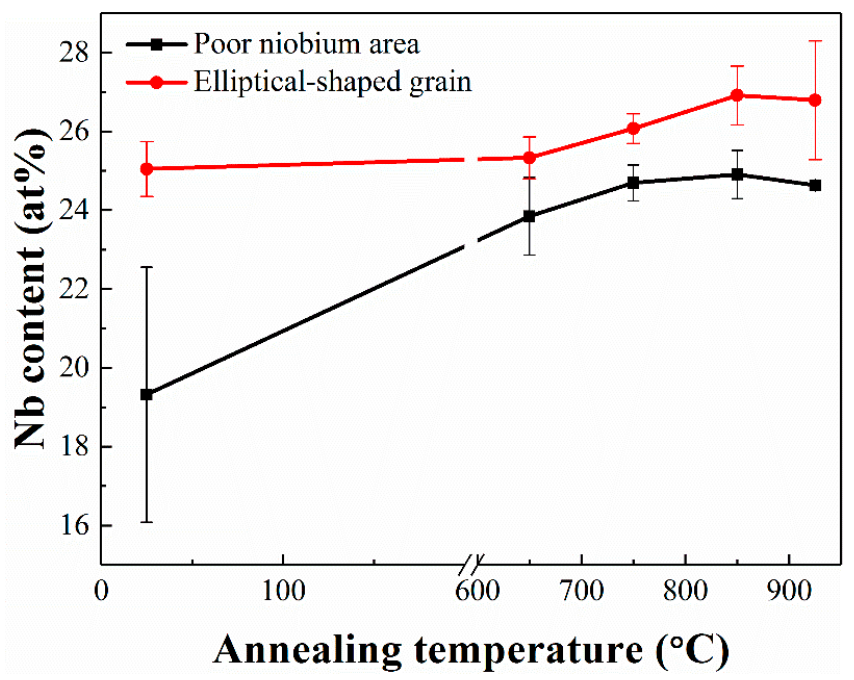

Figure 8. Comparison of $\mathrm{Nb}$ content in different regions of $\mathrm{Ti}-26 \mathrm{Nb}$ alloys after annealing at different temperatures.

\subsection{Grain Orientation and Grain Size}

As mentioned above, the microstructure of the as-deposited Ti-26Nb alloy exhibited columnar $\beta$ grains with fine dendrites inside oriented more or less in the BD. The preferred direction of the dendrite growth in the $\mathrm{Ti}-\mathrm{Nb}$ alloy can be ascribed to the largest thermal gradient parallel to $\mathrm{BD}$ 
during the LAM process, leading to the formation of this texture [25]. The texture was further verified by EBSD orientation maps, as seen in Figure 9a. It is clear that the coarse columnar $\beta$ grains of the as-deposited alloy exhibits a relatively strong $<100\rangle$ fiber texture. The annealing treatment tended to make the grain orientation uniform, as shown in Figure $9 b, c$.
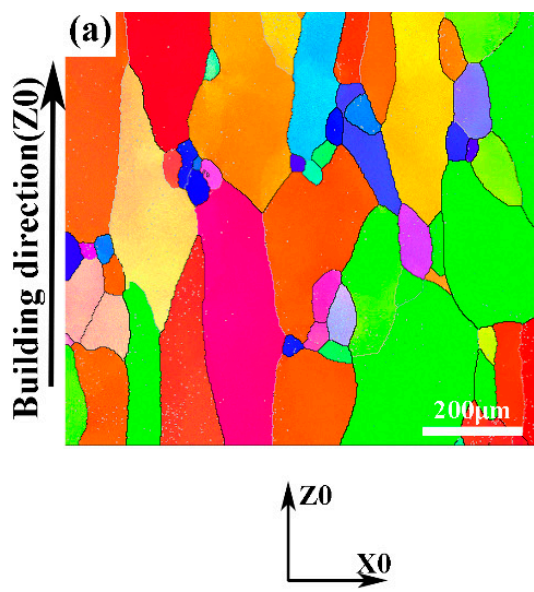

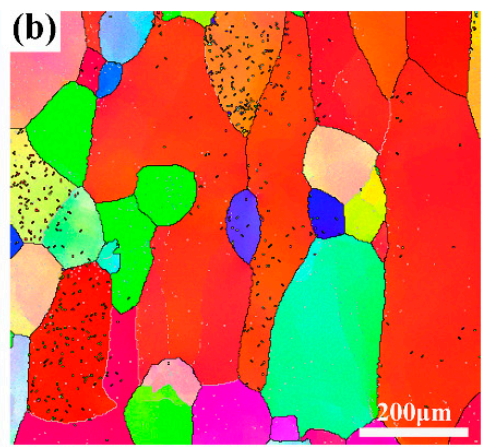

IPF Z0
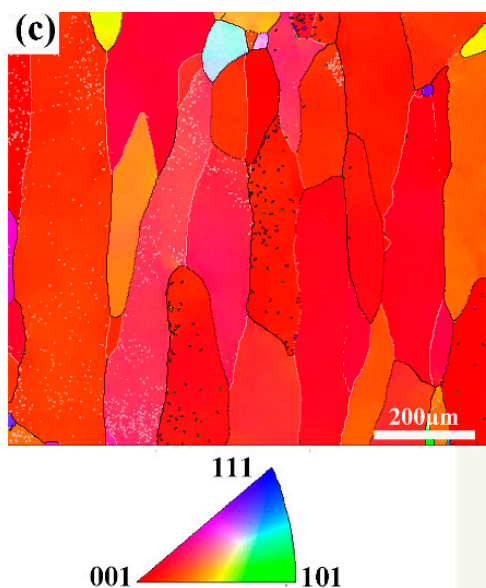

Figure 9. IPFZ electron backscatter diffraction (EBSD) map presented with respect to z-direction showing multiple grain orientations: (a) as-deposited Ti-26Nb alloy; (b) after annealing at $650{ }^{\circ} \mathrm{C}$; (c) after annealing at $850^{\circ} \mathrm{C}$.

Further confirmation of the preferred orientation is illustrated by the corresponding EBSD pole figure in Figure 10. It can be seen that the as-deposited alloy exhibits the strongest $<001>$ texture. After annealing treatment at $650{ }^{\circ} \mathrm{C}$, the $<001>$ texture of the alloy was weakened. However, with the annealing temperature further increasing to $850^{\circ} \mathrm{C}$, the texture became stronger.

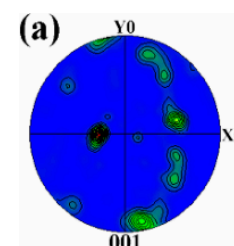

(b)

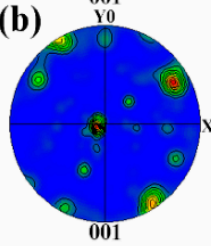

(c)

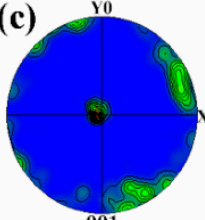

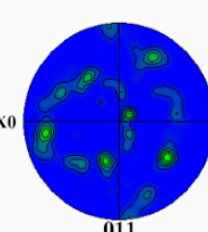
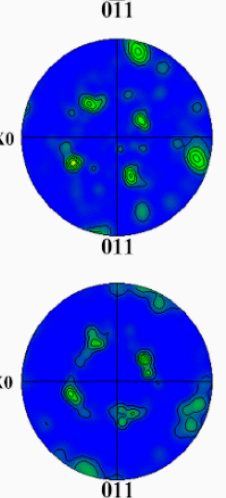
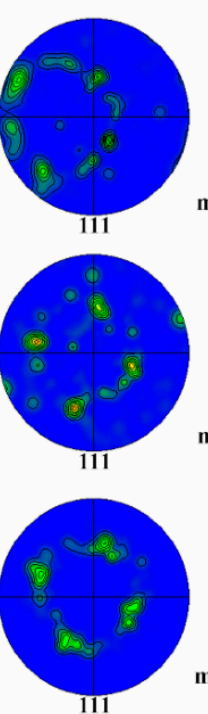

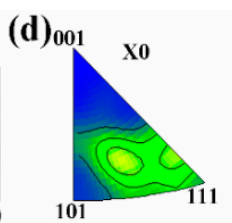

(e) 001
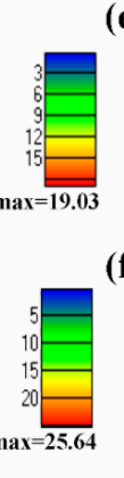

(f)

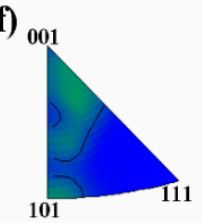

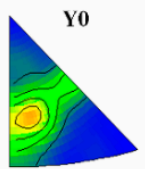

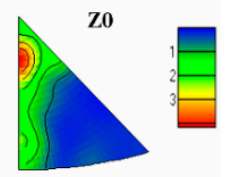

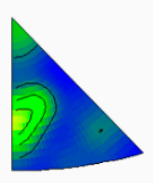
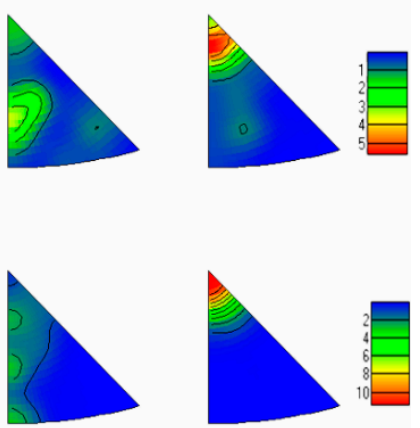

Figure 10. EBSD pole figure and inverse pole figure of Ti-26Nb samples: (a) and (d) as-deposited Ti-26Nb alloy; (b) and (e) after annealing at $650{ }^{\circ} \mathrm{C}$; (c) and (f) after annealing at $850{ }^{\circ} \mathrm{C}$.

The effects of annealing temperature on the columnar grain size of the alloy were also investigated. Figure 11 shows the grain size distribution of the alloy before and after annealing at different temperatures. It can be seen that the average grain size of the as-deposited alloy is about $143.3 \mu \mathrm{m}$. 

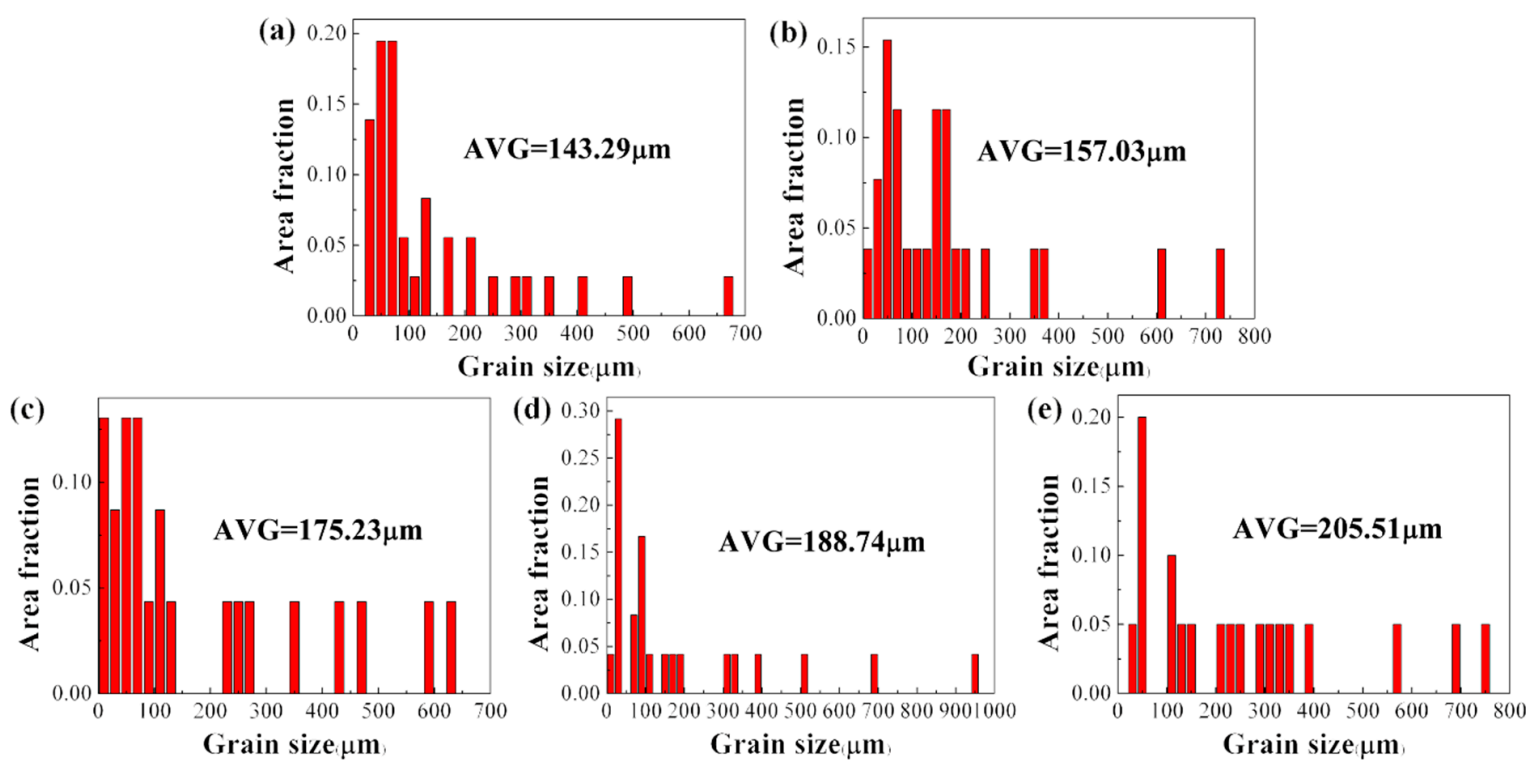

Figure 11. Grain size distributions of specimens: (a) as-deposited Ti-26Nb alloy; (b) after annealing at $650{ }^{\circ} \mathrm{C}$; (c) after annealing at $750{ }^{\circ} \mathrm{C}$; (d) after annealing at $850{ }^{\circ} \mathrm{C}$; (e) after annealing at $925^{\circ} \mathrm{C}$.

While annealing treatment leads to clear growth in the grain size of the columnar $\beta$ grains, with an increase in annealing temperature the size of the columnar $\beta$ grains increases. The alloy after annealing at $925^{\circ} \mathrm{C}$ exhibited the largest grain size, which reached $205.5 \mu \mathrm{m}$. The growth in grain size caused by the heat treatment may have decreased the strength of the alloy.

\subsection{Mechanical Properties}

The stress-strain curves of Ti-26Nb alloys after annealing at different temperatures (see Figure 12). The mechanical properties of the alloy before and after annealing at different temperatures were evaluated by Figure 12 and the results are shown in Figure 13 and Table 2. It can be seen that the as-deposited Ti-26Nb sample shows relatively high strength, with the ultimate tensile strength (UTS) and yield strength (YS) about $799 \mathrm{MPa}$ and $768 \mathrm{MPa}$, respectively, which are much higher than those of the as-rolled Ti-26Nb alloy (see Table 2). The fine-grained structures present inside the $\beta$ grains produced by the rapid solidification process may be responsible for the high strength [26].

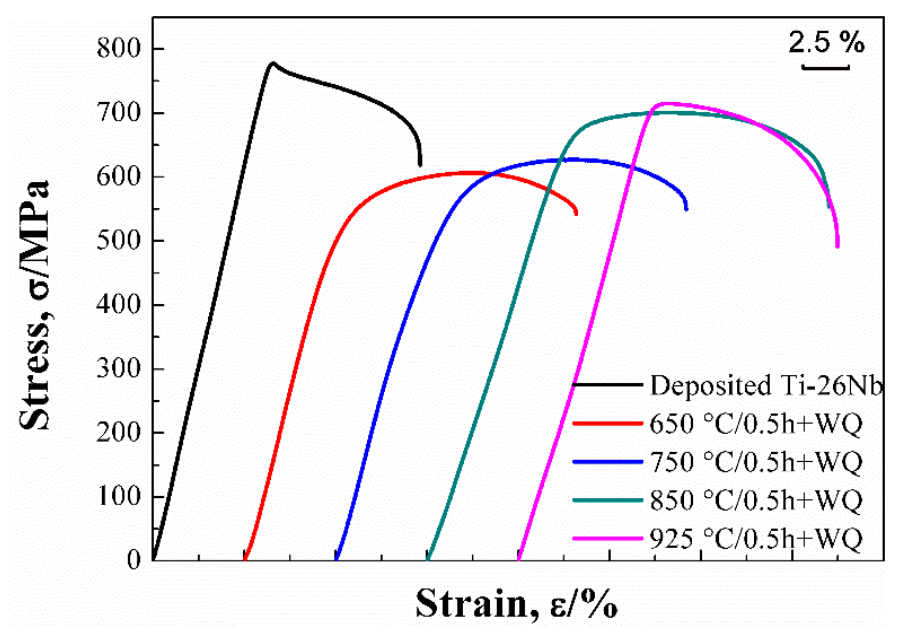

Figure 12. Stress-strain curves of Ti-26Nb alloys after annealing at different temperatures. 


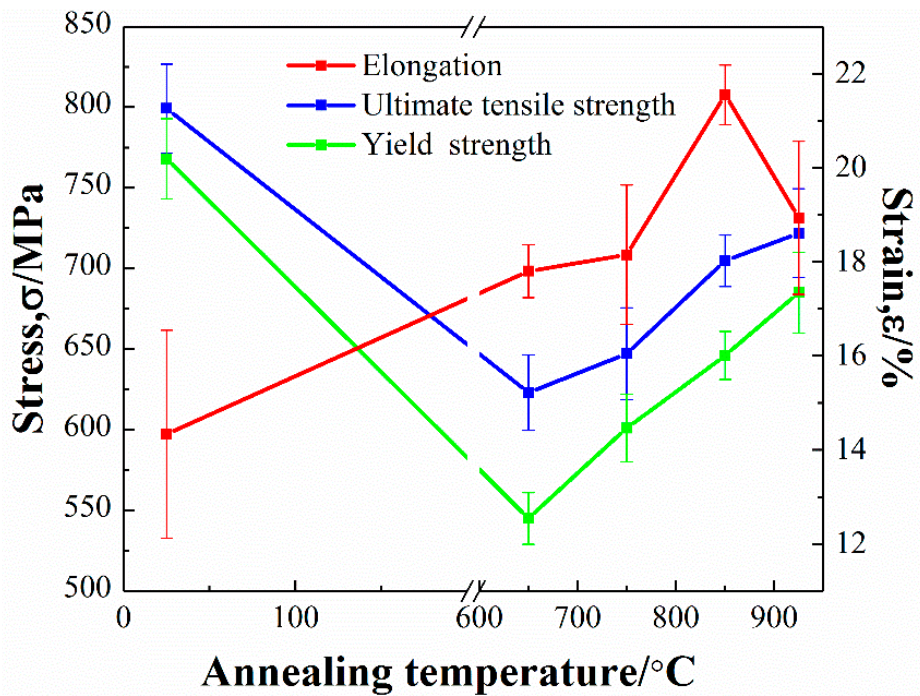

Figure 13. Mechanical properties of Ti-26Nb alloys after annealing at different temperatures.

Table 2. Mechanical properties of Ti-Nb alloys fabricated by LAM and casting.

\begin{tabular}{cccc}
\hline State of Materials & $\begin{array}{c}\text { Ultimate Tensile } \\
\text { Strength/MPa }\end{array}$ & $\begin{array}{c}\text { Yield } \\
\text { Strength/MPa }\end{array}$ & Elongation/\% \\
\hline As-deposited & $799 \pm 27$ & $768 \pm 25$ & $14.3 \pm 2.2$ \\
$650^{\circ} \mathrm{C} / 0.5 \mathrm{~h}+\mathrm{WQ}$ & $623 \pm 23$ & $545 \pm 16$ & $17.8 \pm 0.6$ \\
$750^{\circ} \mathrm{C} / 0.5 \mathrm{~h}+\mathrm{WQ}$ & $647 \pm 28$ & $601 \pm 21$ & $18.2 \pm 1.5$ \\
$850^{\circ} \mathrm{C} / 0.5 \mathrm{~h}+\mathrm{WQ}$ & $704 \pm 16$ & $646 \pm 15$ & $21.6 \pm 0.6$ \\
$925^{\circ} \mathrm{C} / 0.5 \mathrm{~h}+\mathrm{WQ}$ & $722 \pm 27$ & $685 \pm 25$ & $18.9 \pm 1.6$ \\
Hot-rolled of cast Ti-26Nb & $428 \pm 15$ & $415 \pm 12$ & $18.2 \pm 0.8$ \\
\hline
\end{tabular}

The heat treatment decreased the strength but increased the ductility of the alloy, depending on the annealing temperature. It can be seen that, after annealing at $650{ }^{\circ} \mathrm{C}$ for $0.5 \mathrm{~h}$, the UTS and YS of the alloy reduced by about 176 and $223 \mathrm{MPa}$, respectively, in comparison with the as-deposited alloy due to the growth of the prior columnar $\beta$ grains and the dissolution of the fine dendrites [26]. It should be noted that, as the annealing temperature further increased, the strength of the alloys gradually increased despite the growth of the grains. The UTS and YS of the alloy annealed at $925{ }^{\circ} \mathrm{C}$ were about $722 \mathrm{MPa}$ and $685 \mathrm{MPa}$, respectively. The increase in strength of the alloy annealed at a relatively high temperature may be attributable to the solid solution strengthening the effect of the $\mathrm{Nb}$ solute atoms. As mentioned above, annealing treatment can lead to the dissolution of unmelted $\mathrm{Nb}$ atoms into the $\mathrm{Ti}$ lattice and, with an increase in annealing temperature, the content of $\mathrm{Nb}$ in the $\beta$ increases. This may cause more severe lattice distortion, which can increase the resistance of the dislocation motion and consequently promote the strength of the alloy.

With regard to the ductility of the alloy, the as-deposited alloy exhibited relatively low ductility with elongation of $14.3 \%$. This may be attributable to the presence of a large amount of residual stress in the as-built condition and defects such as pores, micro-segregation, and unmelted $\mathrm{Nb}$ particles in the as-deposited alloy. After annealing at $650{ }^{\circ} \mathrm{C}$, the ductility of the alloy slightly increased due to the elimination of residual stress [27] and microstructural homogenization. However, the precipitation of secondary $\alpha$ phases at the grain boundaries may have deteriorated the ductility of the alloy. As the annealing temperature increased to $850^{\circ} \mathrm{C}$, most unmelted $\mathrm{Nb}$ particles dissolved into the $\beta$ phase, which may have increased its stability, and thus no precipitation of secondary $\alpha$ phases occurred. This led to an increase in the ductility of the alloy. As a result, the alloy annealed at $850{ }^{\circ} \mathrm{C}$ exhibited relatively high ductility with elongation of $21.6 \%$. However, with the annealing temperature further increasing to $925^{\circ} \mathrm{C}$, the grains of the $\beta$ phase became coarse, which may have decreased the ductility of the alloy, as its elongation decreased to $18.9 \%$. 


\section{Conclusions}

In this work, a Ti-26Nb alloy was successfully prepared from a mixture of titanium and niobium powders by laser additive manufacturing. The as-deposited alloy was annealed at different temperatures ranging from $650{ }^{\circ} \mathrm{C}$ to $925^{\circ} \mathrm{C}$, then the microstructure evolution and tensile mechanical properties were evaluated. The main conclusions can be summarized as follows:

(1) The microstructure of the as-deposited Ti- $26 \mathrm{Nb}$ alloy was characterized by prior columnar $\beta$ grains with a relatively strong $<001>$ fiber texture due to a large temperature gradient and remelting penetration in the build direction. Defects such as pores, unmelted $\mathrm{Nb}$ particles, and micro-segregation at the grain boundaries of the elliptical-shaped grains could be observed in the as-deposited Ti- $26 \mathrm{Nb}$ alloy. Its ultimate tensile strength and yield strength were about $799 \mathrm{MPa}$ and $768 \mathrm{MPa}$, respectively, much higher than those of hot-rolled Ti-26Nb (428 MPa and $415 \mathrm{MPa}$, respectively).

(2) The heat treatment had an important influence on the microstructures of the as-deposited alloy, depending on the annealing temperature. After annealing at $650{ }^{\circ} \mathrm{C}$ for $0.5 \mathrm{~h}$, many fine acicular secondary $\alpha_{S}$ phases precipitated at the boundaries of the elliptical-shaped grains with poor $\mathrm{Nb}$ content. With the annealing temperature increasing, the unmelted $\mathrm{Nb}$ particles dissolved into the $\mathrm{Ti}$ lattice, leading to an increase in $\mathrm{Nb}$ concentration in the $\beta$ matrix, and the composition of the alloy tended to become uniform by the diffusion of $\mathrm{Nb}$ atoms. Furthermore, the annealing treatment led to growth in the size of the grains.

(3) Heat treatment decreased the strength but increased the ductility of the alloy. After annealing at $650{ }^{\circ} \mathrm{C}$ for $0.5 \mathrm{~h}$, the prior columnar $\beta$ grain growth and fine dendrite dissolution resulted in the ultimate tensile strength and yield strength decreasing to $623 \mathrm{MPa}$ and $543 \mathrm{MPa}$, respectively. The increase in annealing temperature slightly increased the strength of the alloy. The solution strengthening due to the dissolution of the unmelted $\mathrm{Nb}$ particles together with the coarsening of the $\beta$ grains may be responsible for the changing trend of the mechanical properties of the alloy with annealing temperature. The alloy annealed at $850{ }^{\circ} \mathrm{C}$ for $0.5 \mathrm{~h}$ exhibited a good balance of strength and ductility.

Author Contributions: J.W., J.L. and D.Z. designed experiments; J.W. and H.S. carried out experiments; J.L., J.W. and L.G. analyzed experimental results. J.L., D.Z. and C.W. assisted with Illumine sequencing. J.W. wrote the manuscript. J.L. and C.W. revised the paper.

Funding: This research was financially supported by the National Natural Science Foundation of China (11402220, 11872053), Scientific Research Fund of Hunan Provincial Educational Department (2016JC2005) and Hunan Provincial Natural Science Foundation of China (2018JJ4053).

Conflicts of Interest: The authors declare no conflict of interest.

\section{References}

1. Laheurte, P.; Prima, F.; Eberhardt, A.; Gloriant, T.; Wary, M.; Patoor, E. Mechanical properties of low modulus titanium alloys designed from the electronic approach. J. Mech. Behav. Biomed. Mater. 2010, 3, 565-573. [CrossRef] [PubMed]

2. Zhang, D.C.; Mao, Y.F.; Yan, M.; Li, J.J.; Su, E.L.; Li, Y.L. Superelastic behavior of a $\beta$-type titanium alloy. J. Mech. Behav. Biomed. Mater. 2013, 20, 29-35. [CrossRef] [PubMed]

3. Banerjeea, D. Perspectives on titanium science and technology. Acta Mater. 2013, 61, 844-879. [CrossRef]

4. Sun, F.; Hao, Y.L.; Nowak, S.; Gloriant, T.; Laheurte, P.; Prima, F. A thermo-mechanical treatment to improve the superelastic performances of biomedical Ti-26Nb and Ti-20Nb-6Zr (at. \%) alloys. J. Mech. Behav. Biomed. Mater. 2011, 4, 1864-1872. [CrossRef]

5. Ramarolahy, A.; Castany, P.; Prima, F.; Laheurte, P.; Péron, I.; Gloriant, T. Microstructure and mechanical behavior of superelastic Ti-24Nb-0.5 O and Ti-24Nb-0.5 N biomedical alloys. J. Mech. Behav. Biomed. Mater. 2012, 9, 83-90. [CrossRef] [PubMed]

6. Niinomi, M.; Nakai, M.; Hieda, J. Development of new metallic alloys for biomedical applications. Acta Biomater. 2012, 8, 3888-3903. [CrossRef] [PubMed] 
7. Gepreel, M.A.H.; Niinomi, M. Biocompatibility of Ti-alloys for long-term implantation. J. Mech. Behav. Biomed. Mater. 2013, 20, 407-415. [CrossRef]

8. Rao, S.; Okazaki, Y.; Tateishi, T.; Ushida, T.; Ito, Y. Cytocompatibility of new Ti alloy without $\mathrm{Al}$ and V by evaluating the relative growth ratios of fibroblasts L929 and osteoblasts MC3T3-E1 cells. Mater. Sci. Eng. C Mater. Biol. Appl. 1997, 4, 311-314. [CrossRef]

9. Kikuchi, M.; Takahashi, M.; Okuno, O. Mechanical properties and grindability of dental cast Ti-Nb alloys. Dent. Mater. J. 2003, 22, 328-342. [CrossRef]

10. Chang, L.L.; Wang, Y.D.; Ren, Y. In-situ investigation of stress-induced martensitic transformation in Ti- $\mathrm{Nb}$ binary alloys with low Young's modulus. Mater. Sci. Eng. A 2016, 651, 442-448. [CrossRef]

11. Schulze, C.; Weinmann, M.; Schweigel, C.; Keßler, O.; Bader, R. Mechanical properties of a newly additive manufactured implant material based on Ti-42Nb. Materials 2018, 11, 124. [CrossRef] [PubMed]

12. Zhang, Q.; Chen, J.; Tan, H.; Lin, X.; Huang, W.D. Microstructure evolution and mechanical properties of laser additive manufactured Ti-5Al-2Sn-2Zr-4Mo-4Cr alloy. Trans. Nonferr. Metal. Soc. 2016, 26, 2058-2066. [CrossRef]

13. Zhang, L.C.; Klemm, D.; Eckert, J.; Hao, Y.L.; Sercombe, T.B. Manufacture by selective laser melting and mechanical behavior of a biomedical Ti-24Nb-4Zr-8Sn alloy. Scripta Mater. 2011, 65, 21-24. [CrossRef]

14. Wu, X.H.; Liang, J.; Mei, J.F.; Mitchell, C.; Goodwin, P.S.; Voice, W. Microstructures of laser-deposited Ti-6al-4V. Mater. Des. 2004, 25, 137-144. [CrossRef]

15. Baufeld, B.; Brandl, E.; Biest, O.V.D. Wire based additive layer manufacturing: Comparison of microstructure and mechanical properties of Ti-6Al-4V components fabricated by laser-beam deposition and shaped metal deposition. J. Mater. Process. Technol. 2011, 211, 1146-1158. [CrossRef]

16. Fischer, M.; Joguet, D.; Robin, G.; Peltier, L.; Laheurte, P. In situ elaboration of a binary Ti-26Nb alloy by selective laser melting of elemental titanium and niobium mixed powders. Mater. Sci. Eng. C Mater. Biol. Appl. 2016, 62, 852-859. [CrossRef] [PubMed]

17. Wang, Q.; Han, C.; Choma, T.; Wei, Q.; Yan, C.; Song, B.; Shi, Y. Effect of nb content on microstructure, property and in vitro apatite-forming capability of $\mathrm{Ti}-\mathrm{Nb}$ alloys fabricated via selective laser melting. Mater. Des. 2017, 126, 268-277. [CrossRef]

18. Sercombe, T.; Jones, N.; Day, R.; Kop, A. Heat treatment of Ti-6Al-7Nb components produced by selective laser melting. Rapid Prototyp. J. 2008, 14, 300-304. [CrossRef]

19. Vrancken, B.; Thijs, L.; Kruth, J.P.; Humbeeck, J.V. Heat treatment of Ti6Al4V produced by selective laser melting: Microstructure and mechanical properties. J. Alloy. Compd. 2012, 541, 177-185. [CrossRef]

20. Zhu, Y.Y.; Chen, B.; Tang, H.B. Influence of heat treatments on microstructure and mechanical properties of laser additive manufacturing Ti-5Al-2Sn-2Zr-4Mo-4Cr titanium alloy. Trans. Nonferr. Metal. Soc. 2018, 28, 36-46. [CrossRef]

21. Wang, T.; Zhu, Y.Y.; Zhang, S.Q.; Tang, H.B.; Wang, H.M. Grain morphology evolution behavior of titanium alloy components during laser melting deposition additive manufacturing. J. Alloy. Compd. 2015, 632, 505-513. [CrossRef]

22. Li, R.; Shi, Y.; Liu, J. Selective laser melting W-10 wt. \% Cu composite powders. Int. J. Adv. Manuf. Technol. 2010, 48, 597-605. [CrossRef]

23. Kasperovich, G.; Haubrich, J.; Gussone, J.; Requena, G. Correlation between porosity and processing parameters in tial6v4 produced by selective laser melting. Mater. Des. 2016, 105, 160-170. [CrossRef]

24. Yadroitsev, I.; Krakhmalev, P.; Yadroitsava, I.; Johansson, S.; Smurov, I. Energy input effect on morphology and microstructure of selective laser melting single track from metallic powder. J. Mater. Process. Technol. 2013, 213, 606-613. [CrossRef]

25. Chen, W.; Chen, C.; Zi, X.; Cheng, X.; Zhang, X.; Lin, Y.C. Controlling the microstructure and mechanical properties of a metastable $\beta$ titanium alloy by selective laser melting. Mater. Sci. Eng. A 2018, 726, 240-250. [CrossRef]

26. Liu, Y.J.; Li, S.J.; Wang, H.L.; Hou, W.T.; Hao, Y.L.; Yang, R. Microstructure, defects and mechanical behavior of beta-type titanium porous structures manufactured by electron beam melting and selective laser melting. Acta Mater. 2016, 113, 56-67. [CrossRef]

27. Leuders, S.; Thöne, M.; Riemer, A.; Niendorf, T.; Tröster, T.; Richard, H.A. On the mechanical behaviour of titanium alloy Ti6Al4V manufactured by selective laser melting: Fatigue resistance and crack growth performance. Int. J. Fatigue 2013, 48, 300-307. [CrossRef] 
(C) 2018 by the authors. Licensee MDPI, Basel, Switzerland. This article is an open access article distributed under the terms and conditions of the Creative Commons Attribution (CC BY) license (http://creativecommons.org/licenses/by/4.0/). 